Published as: Washington Mhike, Walter W. Focke, Jodi Mackenzie, Edward J. Mills and Heinrich Badenhorst. Stearyl alcohol/palm triple pressed acid-graphite nanocomposites as phase change materials. Thermochimica Acta, 663 (2018) 77-84. https://doi.org/10.1016/j.tca.2018.03.014

\title{
Stearyl alcohol/palm triple pressed acid-graphite nanocomposites as phase change materials
}

Washington Mhike ${ }^{\mathrm{a}}$, Walter W. Focke ${ }^{\mathrm{a}, *}$, Jodi Mackenzie ${ }^{\mathrm{a}}$, Edward J. Mills ${ }^{\mathrm{a}}$ and Heinrich Badenhorst ${ }^{\mathrm{a}}$

anstitute of Applied Materials, Department of Chemical Engineering, University of Pretoria, Private Bag X20, Hatfield 0028, Pretoria, South Africa

\section{Highlights}

- Blends of stearyl alcohol and stearic acid are suitable for thermal energy storage.

- Single melting and crystallization peaks observed in DSC at $35 \mathrm{wt} . \%$ stearyl alcohol.

- Thermal conductivity increased by a factor of six when adding $10 \mathrm{wt} . \%$ nanographite.

\begin{abstract}
Mixtures of stearyl alcohol with palm triple pressed acid (essentially a mixture of palmitic and stearic acid derived from palm oil) were prepared and characterized to assess their phase change thermal energy storage utility. Unlike the other mixtures, the $35 \mathrm{~mol} \%$ stearyl alcohol mixture showed a single crystallization exotherm peak, albeit with a small shoulder, in differential scanning calorimetry. The enthalpy associated with this phase change was $158 \pm$ $5 \mathrm{~kJ} \mathrm{~kg}^{-1}$ and the crystallization peak temperature was $46^{\circ} \mathrm{C}$. Inclusion of $10 \mathrm{wt} . \%$ graphite nanoplatelets increased the solid state and melt state thermal conductivities by factors of approximately six and twelve respectively. This nanocomposite showed no deterioration in thermal properties after hundred heating and cooling cycles between the end-temperatures of $30^{\circ} \mathrm{C}$ and $60^{\circ} \mathrm{C}$ when scanned at a rate of $10^{\circ} \mathrm{C} \mathrm{min}^{-1}$. There was also no evidence of graphite platelet sedimentation in the molten liquid after two months at $80^{\circ} \mathrm{C}$.
\end{abstract}

Key words: Phase change; thermal energy storage; stearyl alcohol; stearic acid; graphite; thermal conductivity

\footnotetext{
* Corresponding author. Tel.: +27 12420 3728: fax: +27 124202516.

E-mail address: walter.focke@up.ac.za (W.W. Focke)
} 


\section{Introduction}

Renewable energy sources, e.g. wind and sunlight, are only intermittently available. Energy storage is necessary to overcome the inevitable disparity between energy demand and supply [1-4]. Phase change materials (PCMs) are attractive options for solar energy storage [2]. They store thermal energy by absorbing and releasing latent heat during phase change transitions at a nearly constant temperature [1-3].

Fatty acids are potential energy storage PCMs [5]. They melt congruently and show negligible super cooling [2]. The latent heats of fusion and crystallization are relatively high [5] and the vapour pressure of the melt is low. They are non-toxic, have good chemical and thermal stability, and are relatively inexpensive [5]. However, fatty acids are mildly corrosive and have an unpleasant door $[2,6]$. Palm triple pressed acid is a bio-based product derived from palm oil that contains palmitic acid (ca. $54 \%$ ) and stearic acid (ca. $43 \%$ ).

Long-chain $n$-alkanols have also been considered as PCMs [7, 8]. The fatty alcohols qualify as phase change materials for energy storage due to their high latent heats of fusion and noncorrosiveness $[9,10]$. However, they exhibit polymorphism which can affect heat storage and extraction [10]. The $\gamma$ polymorph is the stable solid-state form for the higher $n$-alkanols with an even number of carbon atoms [10]. On heating, these ordered phases first transform into a rotator phase, the $\alpha$ form, which subsequently melts. The solid-solid $\gamma \rightarrow \alpha$ phase transition overlaps with the melting $\alpha \rightarrow$ liquid phase transition so that, for the purpose of heat storage, the double transformation appears like a single transition. The $n$-alkanols first crystallize as the $\alpha$ form on cooling. Negligible super cooling has been observed for the liquid $\rightarrow \alpha$ transition. However, significant super cooling can occur for the solid-solid $\alpha \rightarrow \gamma$ transition [9]. This is undesirable and it may cause problems for heat extraction especially when the supercooling exceeds $5^{\circ} \mathrm{C}[2]$.

The solid-solid transition on super cooling is not always detected for compositions near the eutectic point of $n$-alkanols + straight chain fatty acids mixtures [11, 12]. Thus, it might be possible to find an appropriate mixture of palm triple pressed acid and stearyl alcohol, suitable for energy storage, which effectively exhibits an apparent single-phase transition. Mixing $n$-alkanols into fatty acids also lessens the odor and corrosion problems. However, 
only a few studies considered such mixtures for phase change energy storage materials [6, $12-14]$.

The thermal conductivities of stearyl alcohol $\left(0.38 \mathrm{~W} \mathrm{~m}^{-1} \mathrm{~K}^{-1}\right.$ at room temperature $)$ and of stearic acid $\left(0.172 \mathrm{~W} \mathrm{~m}^{-1} \mathrm{~K}^{-1}\right.$ at $\left.70^{\circ} \mathrm{C}\right)$ are relatively low $[1,8]$. These low values constrain the heat storage and extraction rates and therefore the utility of latent heat energy storage systems based on these compounds. Heat exchange can be enhanced by adding either highly thermally conductive particles, e.g. metal or graphite particulates [15], or by impregnation of the PCM into highly thermally conductive porous structures, e.g. graphite foams [16]. Finned configurations, metal matrices and metal insertions can also significantly enhance the heat transfer [15]. However, such approaches inevitably increase costs and compromise the weight of the system [17].

High loadings of conventional thermally conductive fillers are required for appreciable thermal conductivity enhancement [18]. Incorporation of nano-sized particles is a relatively new approach for enhancing the thermal conductivity of PCMs [19]. Dispersion of nanoscale carbons, e.g. nanofibers, nanotubes and graphene in PCMs is of special interest $[4,8,20,21]$. Theoretically, due to their very high thermal conductivities, low loadings should suffice to enhance the thermal conductivity by several orders of magnitude. Instead, the observed improvement in the thermal conductivity is usually rather marginal, for example less than $100 \%$. Simulation studies suggest that the culprit is interfacial thermal resistance [22, 23].

Graphite nanoplatelets (GNPs) are graphite flakes with thicknesses less than 100 nanometers but with lateral dimensions that may extend into the micrometer range [24]. GNPs are conveniently obtained by first thermally exfoliating expandable graphite into graphite nanoplatelet stacks [25] followed by ultrasonic treatment in a suitable liquid medium. This facilitates both flake delamination and the dispersion of the nanoplatelet stacks into the liquid [26]. The in-plane thermal conductivity of GNP flakes can be as high as $5.3 \mathrm{~kW} \mathrm{~m} \mathrm{~K}^{-1}$ while in the perpendicular direction (c-axis of the crystal) it is only $6-30 \mathrm{~W} \mathrm{~m}^{-1} \mathrm{~K}^{-1}$ [27]. Due to the oxidative nature of the intercalation process used to prepare GNPs, oxygen containing functional groups are present on the surface. They enable hydrogen bonding with the alcohol and carboxylic acid groups present in fatty alcohols and fatty acids respectively. This may 
facilitate enhanced interfacial interaction between the graphite nanofiller and the PCM matrix.

The aims of this study were twofold. The first objective was to design a novel PCM based on a mixture of stearyl alcohol with palm triple pressed acid that exhibits a single apparent exotherm at the crystallization transition. The second aim was to find a facile preparation method for enhancing the thermal conductivity of PCMs with GNPs. This communication reports on the thermophysical properties (melting and crystallization enthalpies, thermal conductivity, thermal stability and thermal cyclability, etc.) of such mixtures and nanocomposites.

\section{Experimental}

\subsection{Materials}

Expandable graphite grade ES $250 \mathrm{~B} 5$ (exfoliation onset temperature $220^{\circ} \mathrm{C}$ ) was supplied by Qingdao Kropfmühl Graphite (China). Stearyl alcohol (designated R-OH hereafter) with purity $\geq 96 \%$ was obtained from Merck. Technical grade palm triple pressed acid (designated R-COOH hereafter) was obtained from Pan Century Oleochemical SND BHD, Malaysia. The fatty acid content of this bio-based, palm oil-derived carboxylic acid, as reported by the supplier, is listed in Table 1. Both the stearyl alcohol and the triple pressed acid were used as received, i.e. without further purification.

Table 1. Fatty acid composition of the palm triple pressed acid (Palmac 55-16) reported by the supplier (Pan Century Oleochemical SND BHD, Malaysia)

\begin{tabular}{lllllll}
\hline Fatty acid & $\mathrm{C} 12$ & $\mathrm{C} 14$ & $\mathrm{C} 16$ & $\mathrm{C} 18$ & $\mathrm{C} 18: 1$ & Others \\
Content (wt.\%) & $<1.0$ & $<2.0$ & $52-56$ & $42-47$ & $<0.5$ & $<1.0$ \\
\hline
\end{tabular}

\subsection{Sample preparation}

2.2.1. Graphite exfoliation and delamination. About $3.5 \mathrm{~g}$ of the expandable graphite was exfoliated in a Samsung Model ME9144ST microwave oven at a power setting of $1 \mathrm{~kW}$ and a treatment time of $2 \mathrm{~min}$. About $2 \mathrm{~g}$ exfoliated graphite was combined with $300 \mathrm{~mL}$ isopropanol in a $600 \mathrm{~mL}$ beaker and placed in an ice bath. Ultrasonication was performed for $2 \mathrm{~h}$ at a power setting of $300 \mathrm{~W}$ using a Vibracell VC375 ultrasonic generator with a $12.5 \mathrm{~mm}$ solid tip horn. During this time, the dispersion was agitated continuously with a magnetic stirrer. 
Small portions of the colloidal dispersion of graphite nanoplatelets were deposited on a microscope glass slide and allowed to dry for observation with FESEM and for recording Raman spectra. Another small portion of the dispersion was used for particle size analysis. The dispersion was allowed to stand for a two hours at ambient conditions. During this time, the GNPs settled in a uniform layer at the bottom of the beaker. The excess isopropanol was decanted from the beaker, taking care that the GNPs particles were retained. The dispersion was then ultrasonicated for a further five minutes with mild stirring before being dispersed into the molten PCM mixture.

A portion of the colloidal dispersion was fed into a rotary evaporator (Büchi Rotavapor R114) set at $100^{\circ} \mathrm{C}$. The isopropanol was evaporated until a paste-like consistency was obtained. The paste was dried for $12 \mathrm{~h}$ in a convection oven set at $60^{\circ} \mathrm{C}$. A fluffy, highly friable graphite nanoplatelet aerogel was obtained for characterisation purposes.

\subsubsection{R-OH/R-COOH mixtures. Mixtures of R-OH and R-COOH were prepared by} accurately weighing out the relevant masses into a glass beaker. The mixtures (ca. $10 \mathrm{~g}$ ) were melted on a hot plate controlled to a maximum temperature of $100^{\circ} \mathrm{C}$ and simultaneously stirred with a magnetic stirrer for 5 min after melting. The mixtures were then allowed to cool and solidify before further analysis.

2.2.3. PCM-GNPs nanocomposite. A mixture of stearyl alcohol and palm triple pressed acid containing $35 \mathrm{~mol} \% \mathrm{R}-\mathrm{OH}$ exhibited single crystallization peak (with a small shoulder) in DSC scans. Therefore, it was selected as the phase change material (PCM) matrix. This mixture was melted in a beaker placed on a hot plate with the temperature controlled at $80^{\circ} \mathrm{C}$. The melt was stirred with a magnetic stirrer for $5 \mathrm{~min}$. The ultrasonicated GNPs dispersion was then poured into the molten $\mathrm{R}-\mathrm{OH}+\mathrm{R}-\mathrm{COOH}$ mixture. Stirring was maintained, while the isopropanol evaporated, until the mixture turned into a thick paste. The residual isopropanol was removed from the PCM-GNPs by heating the nanocomposite for $12 \mathrm{~h}$ in a convection oven set at $60^{\circ} \mathrm{C}$. The PCM-GNPs nanocomposites were left to cool and solidify at ambient conditions before further analysis. The PCM-GNPs nanocomposites were prepared at compositions ranging from 0 to $10 \mathrm{wt} . \%$ GNPs. 


\subsection{Material characterization}

2.3.1. Particle size, surface area and density. Graphite particle size distributions were determined with a Mastersizer Hydrosizer 2000 (Malvern Instruments, Malvern, UK). The specific surface areas of the graphite powders were measured with a Micrometrics TriStar BET in $\mathrm{N}_{2}$ at $77 \mathrm{~K}$.

A Micromeritics Accupyc II 1340 fully automated pycnometer was used to determine skeletal densities with helium as the operating gas. The instrument had a $10.00 \mathrm{~cm}^{3}$ sample cup with a $1.00 \mathrm{~cm}^{3}$ insert. Before measurement tests were conducted, a volume calibration was done using the $1.00 \mathrm{~cm}^{3}$ insert. After the calibration, a weighted sample was placed in the sample cup together with the $1.00 \mathrm{~cm}^{3}$ insert so that it was at least two-thirds full. The sample was placed in the instrument sample chamber and the volume of the sample was measured.

2.3.2. Imaging. Graphite particle morphologies were viewed on a Zeiss Ultra Plus 55 ultrahigh resolution field emission scanning electron microscope (FESEM) fitted with an InLens detector. The acceleration voltage was set at $1 \mathrm{kV}$ to ensured maximum resolution of surface detail. No electro-conductive coating was applied on the graphite particles. PCMGNPs nanocomposites were cooled in liquid nitrogen and then fractured.

Optical microscope images of pristine stearyl alcohol, palm triple pressed acid and their mixtures were obtained by placing a small amount of the sample onto the optical microscope hot stage (Linkam CSS 450 platform controlled by LinkSys32 software). The sample was heated until molten, and then cooled at a rate of $0.5^{\circ} \mathrm{C} \mathrm{min}^{-1}$. Images of the crystal structures that formed were captured using a Leica DFC420 digital camera attachment.

2.3.3. Raman spectroscopy. Raman spectra of the various graphite types were recorded using a HORIBA Scientific, Jobin Yvon Technology T6400 series II triple spectrometer system. The $514.5 \mathrm{~nm}$ laser line from a coherent Innnova ${ }^{\circledR} 70 \mathrm{Ar}^{+}$laser was used. The laser power was $10 \mathrm{~mW}$. The CCD detector was liquid nitrogen cooled. An accumulation time of $120 \mathrm{~s}$ was utilized. The Raman spectra were recorded in the wavelength range $500-3500 \mathrm{~cm}^{-1}$ at a resolution of $2 \mathrm{~cm}^{-1}$.

2.3.4. Differential scanning calorimetry (DSC). Melting and crystallization behaviour of ROH, R-COOH and mixtures were studied with a PerkinElmer DSC 4000 instrument. 
Temperature and enthalpy calibrations were performed using $n$-octadecane (melting temperature $27.24^{\circ} \mathrm{C}$ ) and indium (melting temperature $156.60^{\circ} \mathrm{C}$ ) as reference standards. Samples (ca. $5 \mathrm{mg}$ ) were placed in aluminium crucibles with sealed lids. Temperature was scanned from $30^{\circ} \mathrm{C}$ to $70^{\circ} \mathrm{C}$ and back with $5 \mathrm{~min}$ isothermal halts at both end-temperatures. Measurements were done at a heating rate of $0.5^{\circ} \mathrm{C} \mathrm{min}-1$ with nitrogen flowing at $50 \mathrm{~mL}$ $\min ^{-1}$. DSC curves with overlapping peaks were deconvoluted using Lorentzian peaks with MagicPlot software.

2.3.5. Fourier Transform Infrared Spectroscopy (FTIR) was used to determine whether sulfuric acid residues from the oxidative graphite intercalation process catalysed esterification of the R-OH R-COOH PCM mixtures. Spectra were recorded with a Perkin Elmer FTIR fitted with an ATR attachment and represent the average of 32 scans recorded at a resolution of $4 \mathrm{~cm}^{-1}$.

2.3.6. X-ray diffraction (XRD). Molten samples of the stearyl alcohol-palm triple pressed acid mixtures were allowed to cool and solidify in aluminium XRF sample holders before being analysed. X-ray diffraction (XRD) patterns of the mixtures were recorded using a Bruker D8 Advanced powder diffractometer fitted with a Lynx eye detector. Measurements were performed in the $2 \theta$ range $2^{\circ}$ to $90^{\circ}$ with a $0.04^{\circ}$ step size and a counting time of $0.2 \mathrm{~s}$.

2.3.7. Thermal conductivity. Thermal conductivity was measured using a Linseis THB100 Transient Hot bridge instrument fitted with a THB6K/MFR sensor $(42 \times 22 \mathrm{~mm})$. A current of $80 \mathrm{~mA}$ was applied and the measurement time was $20 \mathrm{~s}$. The conductivity in the molten state was measured at $70^{\circ} \mathrm{C}$. Samples were placed in $100 \mathrm{~mL}$ glass containers and immersed in a temperature controlled water bath. The sensor, with its metal frame, was completely immersed in the melt. Five measurements were taken for each sample. The solid state thermal conductivity values were determined at $22^{\circ} \mathrm{C}$. The nanocomposite samples were hot pressed into $3.0 \mathrm{~mm}$ thick sheets at a temperature of $60^{\circ} \mathrm{C}$ and a pressure of $20 \mathrm{MPa}$. These were then cut into two $100 \times 50 \times 3.0 \mathrm{~mm}$ pieces between which the sensor was sandwiched. Triplicate readings were taken for each sample and average values are reported.

2.3.8. Thermal stability of the PCM-GNPs nanocomposites. The stability of the PCMGNPs nanocomposites was evaluated using thermal cycling and settling tests. Thermal 
cycling was performed on the Perkin Elmer DSC 4000 instrument. The PCM-GNPs nanocomposite samples, ca. $5 \mathrm{mg}$, were placed in sealed aluminium pans. One hundred heating and cooling cycles were performed. The temperature was cycled between $30^{\circ} \mathrm{C}$ and $80^{\circ} \mathrm{C}$ at a scan rate of $10^{\circ} \mathrm{C} \mathrm{min}^{-1}$. For the settling tests, nanocomposites containing $0,2.5,5$, and 10 wt.\% GNPs were melted in glass Polytop vials. They were placed in a convection oven set at $80^{\circ} \mathrm{C}$ for two months with intermittent visual inspection.

\section{Results and discussion}

\subsection{Graphite filler properties}

The FESEM micrograph in Figure 1 reveals a creased-flake morphology for the graphite nanoplatelets (GNPs). Table 2 lists the particle sizes and the BET surface areas of the expandable graphite powder and the final graphite nanoplatelets. The thicknesses of the final platelets were in the nano range with lateral dimensions in the micrometer range. According to the particle size analysis, $d_{50}$ size of the nanoplatelets (Table 2) was $13 \mu \mathrm{m}$, almost 30 times smaller than the precursor flakes. It is known that ultrasonication decreases particle size down to a critical size [26].

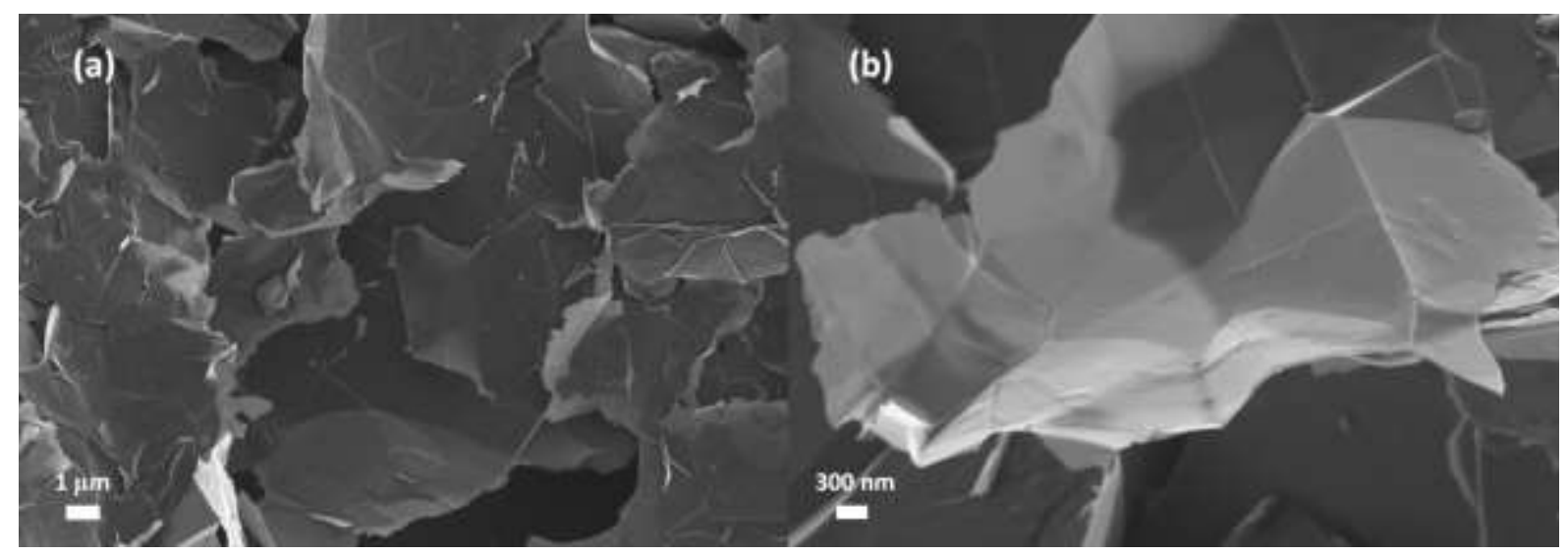

Figure 1. FESEM of graphite nanoplatelets obtained by ultrasonication-assisted liquid phase exfoliation of expanded graphite (Grade ES250 B5) in isopropanol. (a) Low magnification, and (b) high magnification.

According to Table 2, the BET surface area of the GNP aerogel, after solvent removal, was only $12 \mathrm{~m}^{2} \mathrm{~g}^{-1}$. This value is considerably lower than that measured for the exfoliated graphite. The discrepancy is attributed to the re-agglomeration of the graphite platelets during solvent removal. The surface area of the GNPs in the solvent are expected to be considerably higher. However, this could not be confirmed by BET. The aspect ratio of the platelets was estimated by comparing the surface area of the GNP aerogel to that expected for a graphene 
monolayer, i.e. $2700 \mathrm{~m}^{2} \mathrm{~g}^{-1}$ [26]. From this comparison, the average GNP was estimated to consist of 227 graphene sheets with a thickness of about $76 \mathrm{~nm}$ and an average aspect ratio of $w / t \approx 171$

Table 2. Particle size, BET surface area and density of graphite samples derived from expandable graphite grade ES250 B5

\begin{tabular}{lccccc}
\hline Graphite & \multicolumn{3}{c}{ Particle size, $\boldsymbol{\mu m}$} & BET & Density \\
\hline form & $d_{10}$ & $d_{50}$ & $d_{90}$ & $\mathrm{~m}^{2} \mathrm{~g}^{-3}$ & $\mathrm{~g} \mathrm{~cm}^{-3}$ \\
Expandable (neat) & 144 & 381 & 642 & 2.40 & $2.08 \pm 0.01$ \\
Exfoliated & & - & & $41 \pm 3$ & $0.009 \pm 0.001^{\dagger}$ \\
Sonicated & 5 & 13 & 36 & $12 \pm 1^{*}$ & $2.26 \pm 0.19^{\#}$ \\
\hline
\end{tabular}

"Surface area of the aerogel after solvent removal. ${ }^{\dagger}$ Apparent density. "Skeletal density of the dried aerogel determined with a Micrometrics AccuPyc II 1340 helium gas pycnometer. Reported uncertainties correspond to one standard deviation ( 0.68 level of confidence).

The Raman spectrum of Figure 2 indicates a highly graphitic nature for the graphite nanoplatelets. The ratio of the peak intensity of the D-band $\left(1350 \mathrm{~cm}^{-1}\right)$ to that of the G-band $\left(1582 \mathrm{~cm}^{-1}\right)\left(I_{D} / I_{G}\right)$ provides a measure for the imperfection of graphitic carbons [28]. The $I_{D} / I_{G}$ ratio for the expandable graphite was 0.63 and for the graphite nanoplatelets it was 0.03 . The measured density of the latter $\left(2.26 \mathrm{~g} \mathrm{~m}^{-3}\right)$ was comparable to that of pure graphite.

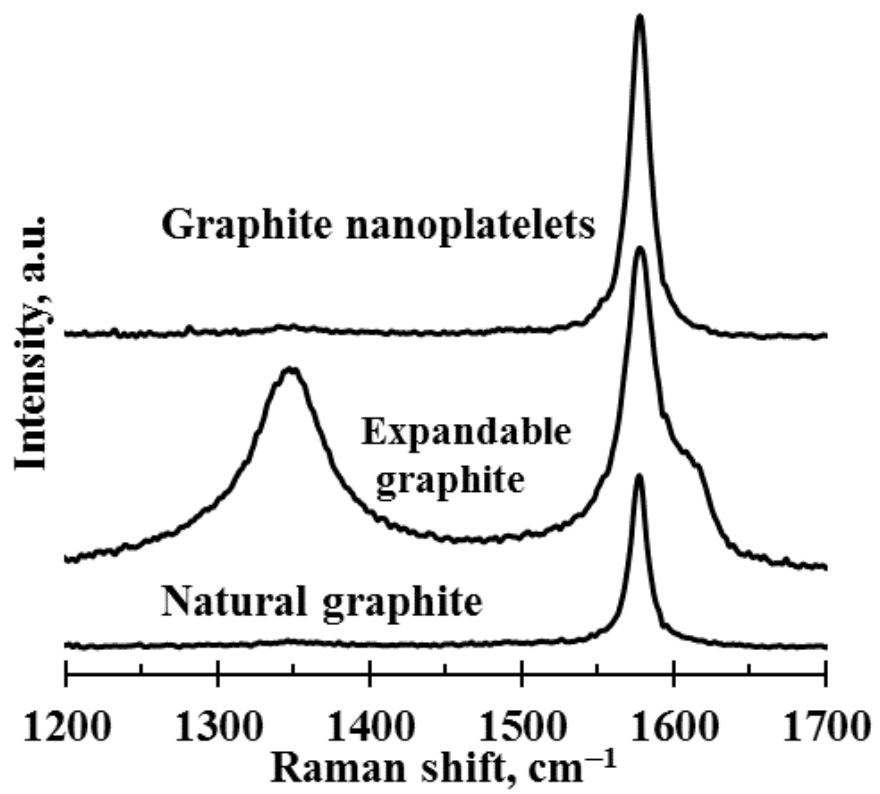

Figure 2. Raman spectra of expandable graphite and the graphite nanoplatelets (GNPs) compared to natural graphite. 

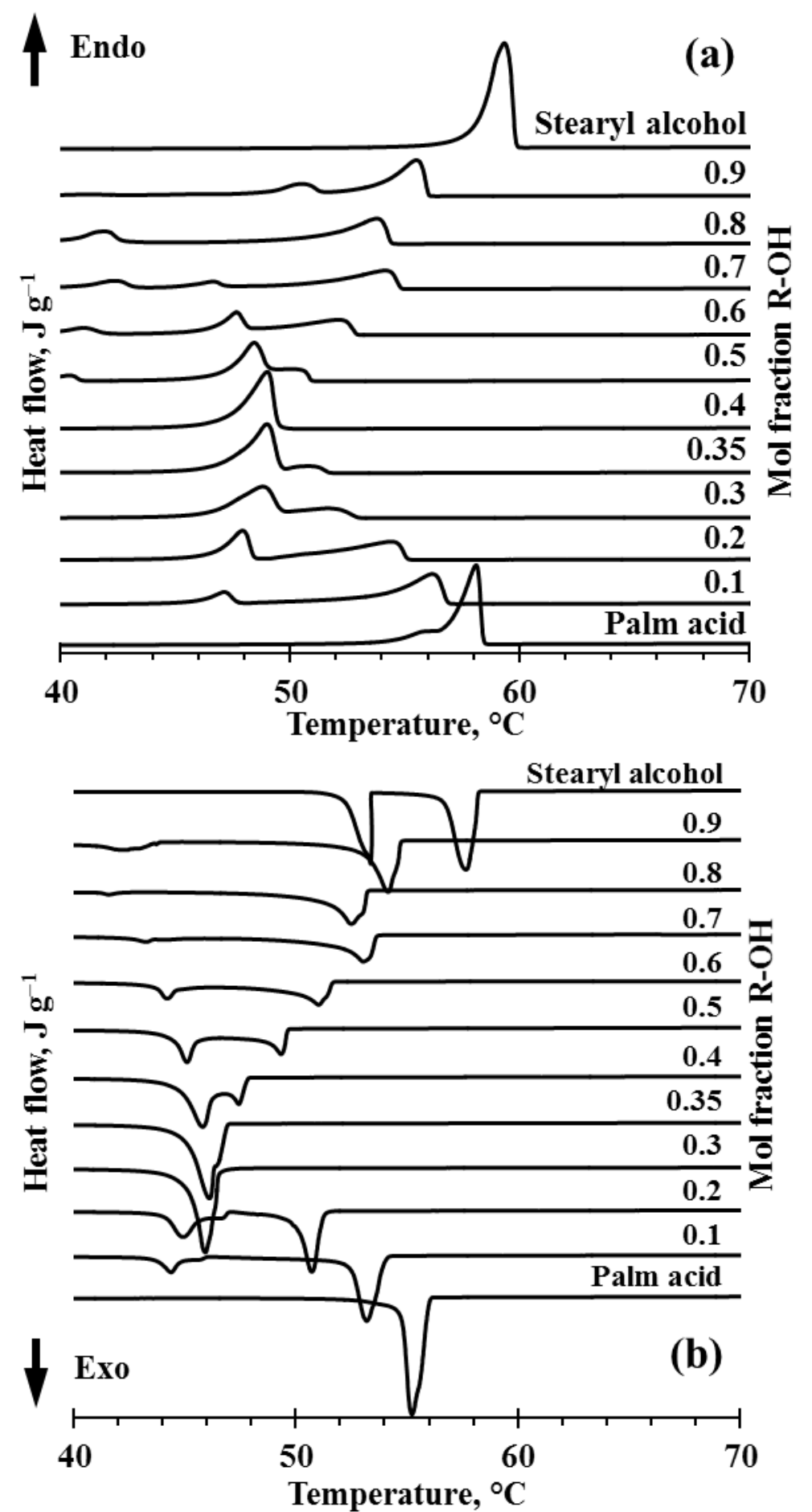

Figure 3. DSC heating and cooling curves for mixtures of stearyl alcohol with palm triple pressed acid.

\subsection{Stearyl alcohol-palm triple pressed acid (R-OH+R-COOH) mixtures}

3.2.1. Melting and crystallization characteristics. Figure 3 shows the second heating and cooling DSC scans for mixtures of stearyl alcohol with palm triple pressed acid. The heating curve of stearyl alcohol showed only one endotherm with an onset temperature of $58.1^{\circ} \mathrm{C}$, which agrees with the value reported by Ksiązczak and Parczewska [29] but it is slightly 
lower than the $58.7^{\circ} \mathrm{C}$ stated by Maximo et al. [30]. This means that the solid-solid transition from the monoclinic ordered $\gamma$ phase to the $\alpha$ rotator phase overlapped with the melting transition [10]. However, the cooling curve for stearyl alcohol did exhibit two exotherms. The first exotherm with an onset temperature of $57.8^{\circ} \mathrm{C}$ showed negligible super cooling. The solid-solid $\gamma \rightarrow \alpha$ transition did exhibit super cooling approaching $5^{\circ} \mathrm{C}$, the threshold for proper heat extraction from the PCMs [2].

The commercial palm triple pressed acid is in fact a combination of approximately $54 \%$ palmitic acid (saturated fatty acid with 16 carbon atoms), 43\% stearic acid (saturated fatty acid with 18 carbons) plus other fatty acids [31]. Table 1 reports the composition of the palm triple pressed acid as indicated by the manufacturer. The estimated mean molar mass of this mixture $\left(268 \mathrm{~g} \mathrm{~mol}^{-1}\right)$ is very close to that of stearyl alcohol $\left(270.5 \mathrm{~g} \mathrm{~mol}^{-1}\right)$. The heating and cooling curves for this of palm triple pressed acid are shown in Figure 3. They feature one melting endotherm and a single crystallization endotherm. The melting endotherm did, however, feature a small shoulder. Mixtures of pure stearic acid and palmitic acid show eutectic behaviour [31]. The melting temperature of the palm triple pressed acid (onset 56.8 ${ }^{\circ} \mathrm{C}$, peak $\left.58.1^{\circ} \mathrm{C}\right)$ used in this study is lower than that of pure stearic acid $\left(69.3^{\circ} \mathrm{C}\right)$ but close to the value indicated by the phase diagram for the stearic acid-palmitic acid system [31].

An attempt was made to solve the stearyl alcohol super cooling problem by adding palm triple pressed acid. Similar mixtures, using stearic acid, were studied previously [11]. The palm triple pressed acid was treated as a pseudo-single component. The mixtures with stearyl alcohol can therefore be considered pseudo-binary mixtures [32]. Figure 3 also shows the second DSC heating curves of pseudo-binary mixtures as a function of the stearyl alcohol (R$\mathrm{OH})$ content. In agreement with previous studies, the curves feature multiple endotherms [1114]. The higher temperature endotherms (solid-liquid transitions) go through a minimum at around 0.4 mole fraction $\mathrm{R}-\mathrm{OH}$. This behaviour is characteristic of a eutectic system as previously observed for of mixtures of $n$-alkanols with straight chain fatty acids [11-14]. Such an eutectic system features miscibility in the liquid phase and de-mixing and segregation in the solid phase [11].

The simplified phase diagram for the pseudo-binary mixtures is shown in Figure 4 and was constructed using the peak transitions temperatures in the DSC heating run (Table 3). The 
endotherm peak temperatures, rather than the onset temperatures, were used as they reportedly provide a better representation of the transitions [13, 33]. Also shown in Figure 4 are the van't Hoff freezing point depression curves that define the solid-liquidus equilibrium lines for ideal binary liquid mixtures $[11,14]$ :

$$
\ln x_{i}=\frac{\Delta H_{i}}{R}\left(\frac{1}{T_{i}}-\frac{1}{T}\right)
$$

where $x_{i}, \Delta H_{i}$ and $T_{i}$ are the mole fraction, heat of fusion and melting temperature of pure compound $i$, respectively; $R$ is the universal gas constant and $T$ the melting temperature of the mixture. This equation can also be applied to pseudo-binary mixtures [32]. The predicted liquidus temperatures and the eutectic temperature are in approximate agreement with the experimental data. However, a closer examination of the experimental data indicates that the liquidus line features another minimum at around 0.8 mole fraction stearyl alcohol suggesting that there are two eutectic points. Two eutectic compositions are features of systems in which co-crystallization occurs [34]. The XRD results support this hypothesis for the present sample mixtures. The XRD traces supplied in the supplementary information (Figure S1) indicates the presence of two distinct crystalline phases at 0.4 and 0.8 mole fractions $\mathrm{R}-\mathrm{OH}$ respectively as the XRD patterns differ from those for the pure components.

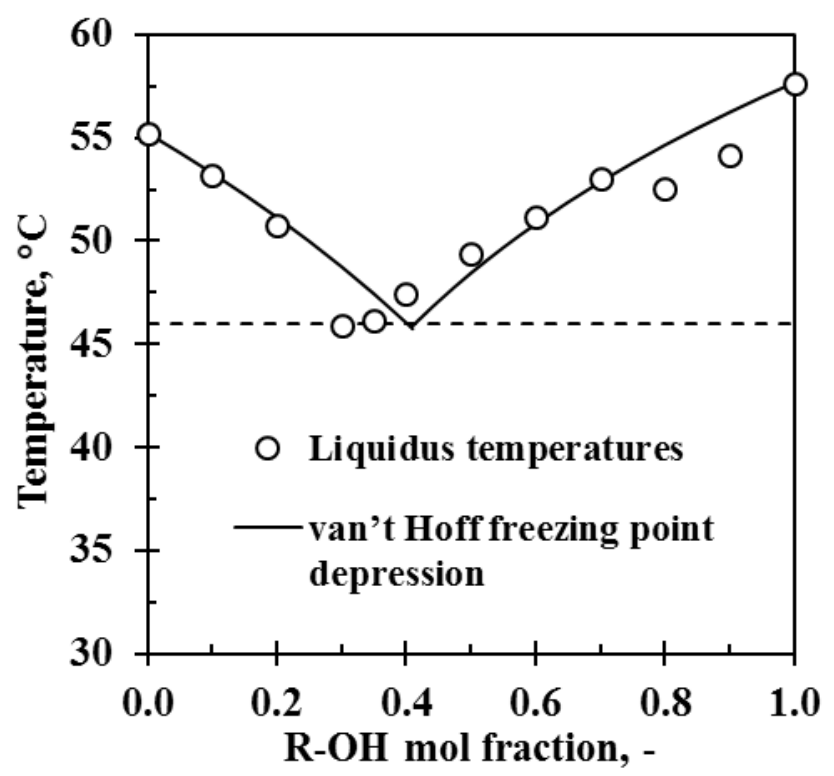

Figure 4. Simplified phase diagram for the pseudo-binary mixture of stearyl alcohol with palm triple pressed acid. 
Table 3. Transition temperatures and total phase transition enthalpy for mixtures of stearyl alcohol and palm triple pressed acid from the second DSC heating run ${ }^{\dagger}$. Temperature was scanned at $10^{\circ} \mathrm{C} \mathrm{min}^{-1}$

\begin{tabular}{|c|c|c|c|c|c|}
\hline \multirow{2}{*}{$\begin{array}{l}\mathrm{R}-\mathrm{OH} \\
\mathrm{mol} \%\end{array}$} & \multicolumn{4}{|c|}{ Transition peak temperatures, ${ }^{\circ} \mathrm{C}$} & \multirow{2}{*}{$\begin{array}{c}\text { Enthalpy } \\
\qquad \mathrm{J} \mathrm{g}^{-1}\end{array}$} \\
\hline & $1^{\text {st }}$ solid & $2^{\text {nd }}$ solid $^{\dagger}$ & Eutectic & Melting & \\
\hline 0 & & & & 58.1 & $179 \pm 2$ \\
\hline 10 & & & 47.1 & 56.2 & 192 \\
\hline 20 & & & 47.9 & 54.5 & 182 \\
\hline 30 & & & 48.8 & 51.8 & 172 \\
\hline 35 & & & 49.0 & 51.0 & $160 \pm 8$ \\
\hline 40 & 38.7 & & 49.0 & 49.0 & 214 \\
\hline 50 & 36.2 & 42.0 & 48.4 & 55.0 & 207 \\
\hline 60 & 33.9 & 41.1 & 47.7 & 52.2 & 211 \\
\hline 70 & 33.6 & 42.0 & 46.6 & 54.2 & 240 \\
\hline 80 & & 41.7 & & 53.8 & 231 \\
\hline 90 & & 41.4 & 55.0 & 55.5 & 257 \\
\hline 100 & & & & 59.3 & $248 \pm 1$ \\
\hline
\end{tabular}

$\dagger$ Values obtained after peak separation by deconvolution. *Total transition enthalpy

Reported uncertainties correspond to one standard deviation ( 0.68 level of confidence).

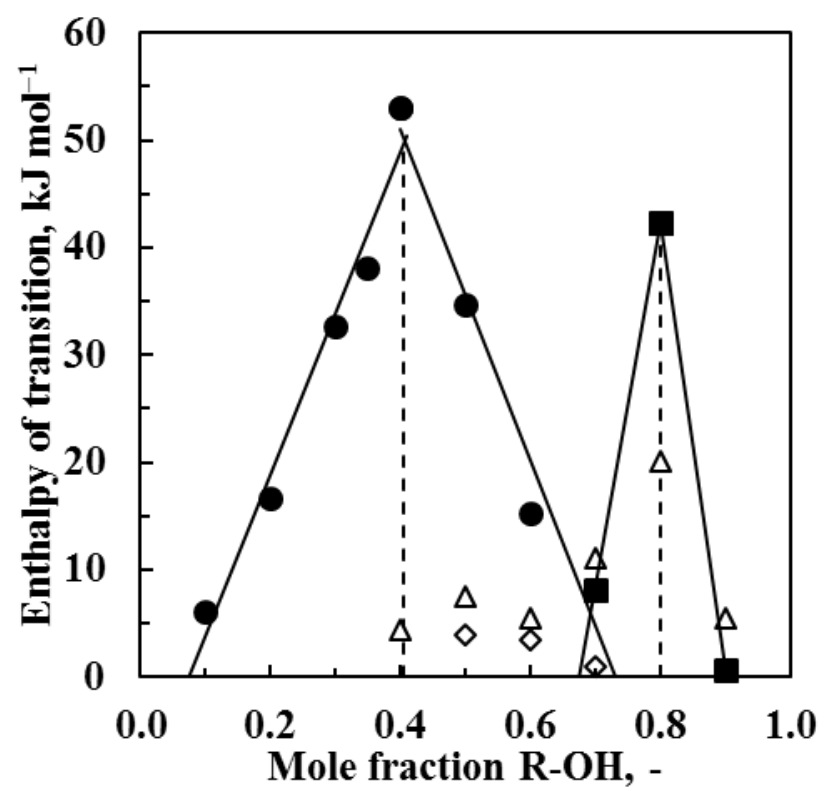

Figure 5. Tamman plot for pseudo-binary mixtures of stearyl alcohol with palm triple pressed acid: solid-liquid transitions; $\triangle \& \diamond$ solid-solid transitions.

A Tamman diagram is a plot of the molar enthalpies of the DSC endotherms associated with the eutectic transition as a function of the mixture molar composition [35, 36]. A simple eutectic will exhibit a maximum in the molar enthalpies at the eutectic point, forming a 
triangular plot. The Tamman plot also reveals the composition range in which solid solubility exists $[35,36]$. The Tamman plot of Figure 5 supports the contention that the pseudo-binary system has a bi-eutectic nature with eutectic compositions at approximately 0.40 and 0.80 mole fraction $\mathrm{R}-\mathrm{OH}$.

However, a thorough analysis of the DSC results (see Figure 3) reveals that the actual behaviour is much more complex. Table 3 lists the observed transition temperatures and the corresponding enthalpies. Between 0.4 and 0.9 mole fraction $\mathrm{R}-\mathrm{OH}$ additional endotherms appear before the eutectic temperatures are reached. These were previously assigned to the effect of the solid transition in the alcohol [11]. However, it could be that partial solubility of the components in the solid state and/or that the impurities present in the palm triple pressed acid also played a role.

Despite this complex behaviour, the system nevertheless approximates to a single apparent melting phase transition close to the expected value of 0.4 mole fraction $\mathrm{R}-\mathrm{OH}$. However, at exactly this value the DSC cooling curve (Figure 3) show a small secondary peak. This weakens to a shoulder on the main peak at $35 \mathrm{~mol} \% \mathrm{R}-\mathrm{OH}$. For this reason, the latter composition was selected as the PCM for further study. An examination of the data in Table 3 indicates a complex variation of the total melting enthalpy with composition. It increases from the low value for the commercial palm triple pressed acid $\left(179 \mathrm{~J} \mathrm{~g}^{-1}\right)$, through a minimum value of approximately $160 \mathrm{~J} \mathrm{~g}^{-1}$ at 0.35 mole fraction $\mathrm{R}-\mathrm{OH}$, to a maximum for the neat stearyl alcohol $\left(248 \mathrm{~J} \mathrm{~g}^{-1}\right)$. The latter value is lower than the $257 \mathrm{~J} \mathrm{~g}^{-1}$ reported by Nichols et al. [37] but higher that the $242 \mathrm{~J} \mathrm{~g}^{-1}$ stated by Maximo et al. [30]. Optical microscope pictures acquired during crystallization showed that the formation of much smaller crystals may explain the reduced enthalpy value (Figure S2, supplementary information). Gandolfo et al. [38] also previously observed smaller crystals for mixtures of stearyl alcohol and stearic acid. XRD studies [39] indicated that these were mixed crystals of stearyl alcohol and stearic acid. Nevertheless, the magnitude of the phase change enthalpy is still comparable to those of other materials considered for PCMs energy storage $[1,2]$ with negligible super cooling (Table 4). 
Table 4. Melting and crystallization temperatures and enthalpies of the PCM-GNP nanocomposites from the DSC second heating cycle. Temperature was scanned at $10^{\circ} \mathrm{C} \min ^{-1}$

\begin{tabular}{cc|ccc|lll}
\hline $\begin{array}{c}\text { Composition } \\
\text { R-OH }\end{array}$ & \multicolumn{3}{|c|}{ Melting } & \multicolumn{3}{c}{ Crystallization } \\
$(\mathrm{mol} \%)$ & $\begin{array}{c}T_{\text {onset }} \\
(\text { wt.\% })\end{array}$ & $\begin{array}{l}T_{\text {peak }} \\
\left({ }^{\circ} \mathrm{C}\right)\end{array}$ & $\begin{array}{l}\left.{ }^{\circ} \mathrm{C}\right) \\
\left(\mathrm{J} \mathrm{g}^{-1}\right)\end{array}$ & $\begin{array}{l}T_{\text {onset }} \\
\left({ }^{\circ} \mathrm{C}\right)\end{array}$ & $\begin{array}{l}T_{\text {peak }} \\
\left({ }^{\circ} \mathrm{C}\right)\end{array}$ & $\begin{array}{c}\text { Enthalpy } \\
\left(\mathrm{J} \mathrm{g}^{-1}\right)\end{array}$ \\
\hline 100 & 0 & $58.1 \pm 0.1$ & $59.4 \pm 0.1$ & $248 \pm 1$ & $58.3 \pm 0.1$ & $57.6 \pm 0.1$ & $245 \pm 1$ \\
0 & 0 & $56.8 \pm 0.0$ & $58.1 \pm 0.0$ & $179 \pm 2$ & $56.1 \pm 0.1$ & $55.2 \pm 0.0$ & $185 \pm 2$ \\
35 & 0 & $47.4 \pm 0.1$ & $49.0 \pm 0.0$ & $160 \pm 8$ & $46.6 \pm 0.0$ & $46.0 \pm 0.1$ & $158 \pm 5$ \\
35 & 2.5 & $46.0 \pm 1.3$ & $48.4 \pm 0.3$ & $158 \pm 15$ & $48.0 \pm 1.8$ & $45.9 \pm 0.2$ & $156 \pm 15$ \\
35 & 5.0 & $46.2 \pm 0.6$ & $48.3 \pm 0.3$ & $159 \pm 19$ & $47.6 \pm 1.4$ & $46.2 \pm 0.4$ & $159 \pm 15$ \\
35 & 10 & $45.2 \pm 1.7$ & $47.8 \pm 0.8$ & $136 \pm 11$ & $47.2 \pm 1.4$ & $45.6 \pm 0.5$ & $132 \pm 11$ \\
\hline
\end{tabular}

Reported uncertainties correspond to one standard deviation (0.68 level of confidence)

\subsection{PCM-GNPs nanocomposites}

As mentioned previously, solvent removal, following ultrasonic exfoliation, resulted in reagglomeration of GNPs nanoplatelets. To prevent this, the molten PCM was added to the GNP dispersion and the mixture homogenized before the solvent was removed by evaporation. This approach should have prevented significant re-agglomeration or at least significantly reduced it.

3.3.1. Morphology and structure. Figure 6 shows FESEM micrographs of the morphology of the PCM-GNPs nanocomposites. Figure 6(a), shows the structure of graphite nanoplatelets in the PCM containing 2.5 wt.\% GNPs. The sheet thicknesses are less than $50 \mathrm{~nm}$. This suggests that the new preparation approach (to prepare the nanocomposite directly from the ultrasonication-assisted liquid phase exfoliated graphite dispersion), was successful in delaminating and dispersing the nanoplatelets within the PCM. The GNPs appear completely covered by the PCM. Figure 6(b) shows that, at $10 \mathrm{wt} . \%$, the well-dispersed and randomly oriented GNPs particles form a space-filling interconnected network capable of trapping the PCMs interstitially. As the PCM-GNPs nanocomposite undergoes plentiful melt/freeze cycles during its lifetime, it is important that this structure remains stable to prevent sedimentation of the graphite nano-platelets. The morphology shown in Figure 6(b) suggests that the formation of the GNPs network may well offer the required stability to prevent this from happening. 


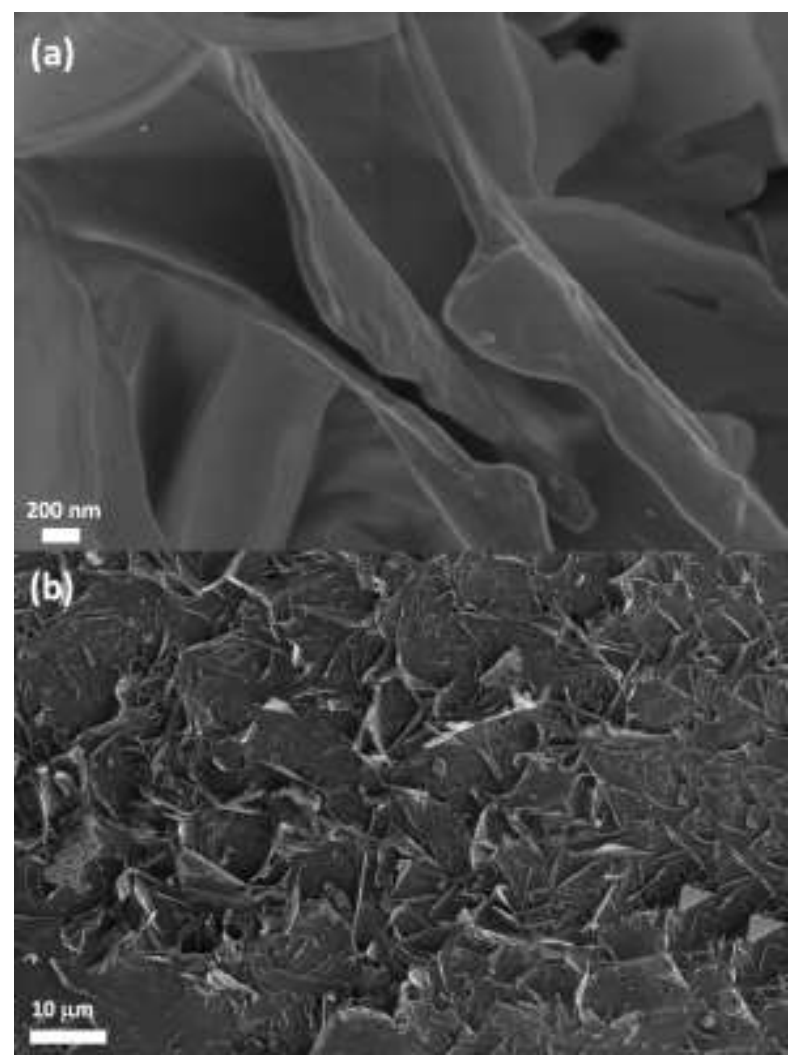

Figure 6. FESEM micrographs of stearyl alcohol-palm triple pressed acid PCM-graphite nanocomposites loaded with (a) $2.5 \mathrm{wt} . \%$, and (b) $10 \mathrm{wt} . \%$ graphite.

3.3.2. FTIR. Acidic groups present on the graphite surfaces may well catalyse the esterification reaction between stearyl alcohol and the fatty acids. The fatty acid carbonyl stretching vibration band is found in the range 1700-1725 $\mathrm{cm}^{-1}$ [40] while the spectra for esters band is located at ca. $1732 \mathrm{~cm}^{-1}$. Ester formation did occur when the PCM-GNPs nanocomposites were prepared at $150^{\circ} \mathrm{C}$ as a new absorption band at ca. $1732 \mathrm{~cm}^{-1}$ appeared in the FTIR spectrum. However, for PCM-GNPs compounded below $100^{\circ} \mathrm{C}$, no such band was observed in the FTIR spectra (Figure S3, supplementary information). Hence all the PCM-GNPs nanocomposites tested presently, were prepared at the even lower temperature of $80^{\circ} \mathrm{C}$.

3.3.3. Melting and crystallization temperatures and enthalpies. Figure 7 shows the second DSC heating and cooling runs of the PCM/graphite nanocomposites. The onset and peak temperatures and enthalpies of melting derived from DSC runs are reported in Table 4. Figure 7 and Table 4 show that, compared to the neat mixtures, the peak and melting onset temperatures decreased slightly as the graphite content increased. At $10 \mathrm{wt} . \%$ graphite the 
decrease was slightly more than $1^{\circ} \mathrm{C}$. As expected, the melting and crystallization enthalpies also decreased with graphite content. At $10 \mathrm{wt} . \%$ graphite, the melting and crystallization enthalpies were about $20 \%$ lower than than the value for the neat PCM, i.e. in the absence of graphite. The deterioration exceeds the amount attributable to the replacement of the phase change material by graphite. However, the PCM/graphite nanocomposites featured negligible super cooling.

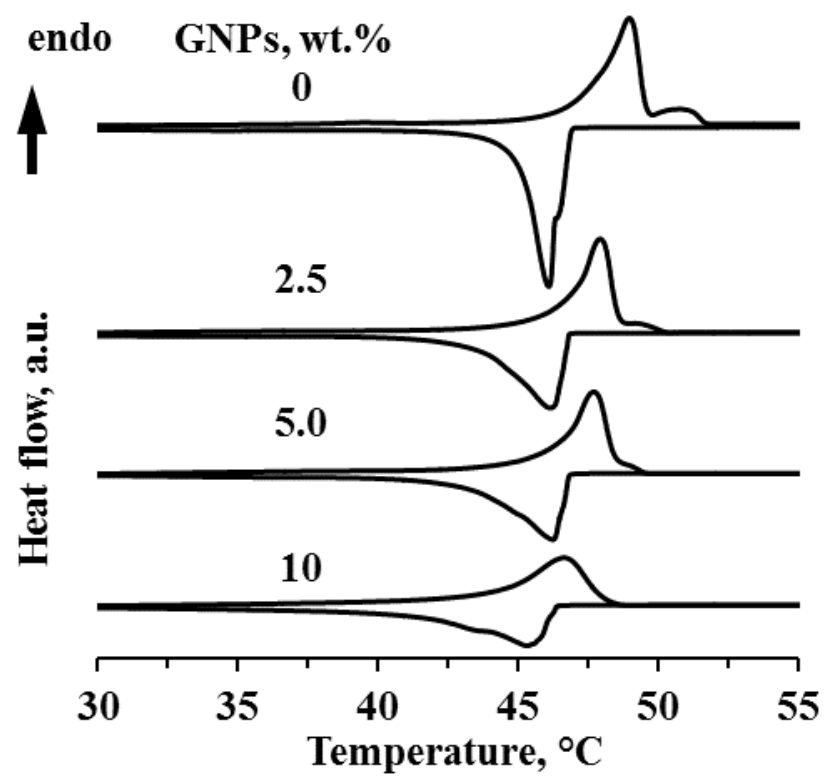

Figure 7. DSC heating and cooling curves of stearyl alcohol-palm triple pressed acid PCM-graphite nanocomposites. The PCM phase contained 35 mol\% stearyl alcohol.

3.3.4. Thermal conductivity. It is desirable to minimize the amount of conductive filler to keep the enthalpy of phase change per unit mass or unit volume as high as possible. The thermal conductivity results are reported in Table 5. In agreement with the results of Wang et al. [41], the thermal conductivity of the PCM-GNPs (Table 5) were marginally higher in the solid state. However, at $10 \mathrm{wt} . \%$, the conductivity measured in the molten state was anomalously higher than in the liquid state. The conductivity was substantially enhanced in both the the solid and molten states. At $10 \mathrm{wt} . \%$ (4.2 vol.\%) graphite content, the thermal conductivity of the solid was about six times higher and in the liquid state it was twelve times better. The present findings are comparable to measurements obtained with GNPs dispersed in paraffin wax [21, 42] and graphene dispersed in stearyl alcohol [8]. However, other approaches utilizing other highly conductive nanofillers, at best, only managed to double the conductivity at comparable loadings $[4,7,20,21,41]$. 
Table 5. Thermal conductivity $\left(\mathrm{W} \mathrm{m}^{-1} \mathrm{~K}^{-\mathbf{1}}\right)$ of the PCM/graphite nanocomposites based on 35 mol\% stearyl alcohol in the solid state $\left(22^{\circ} \mathrm{C}\right)$ and in the molten state $\left(70^{\circ} \mathrm{C}\right)$

\begin{tabular}{ccc}
\hline Graphite, wt.\% & Solid state & Molten state \\
0 & $0.252 \pm 0.002$ & $0.177 \pm 0.014$ \\
2.5 & $0.565 \pm 0.001$ & $0.359 \pm 0.014$ \\
5.0 & $0.833 \pm 0.003$ & $0.614 \pm 0.024$ \\
10.0 & $1.687 \pm 0.009$ & $2.311 \pm 0.027$ \\
\hline
\end{tabular}

Reported uncertainties correspond to one standard deviation (0.68 level of confidence)

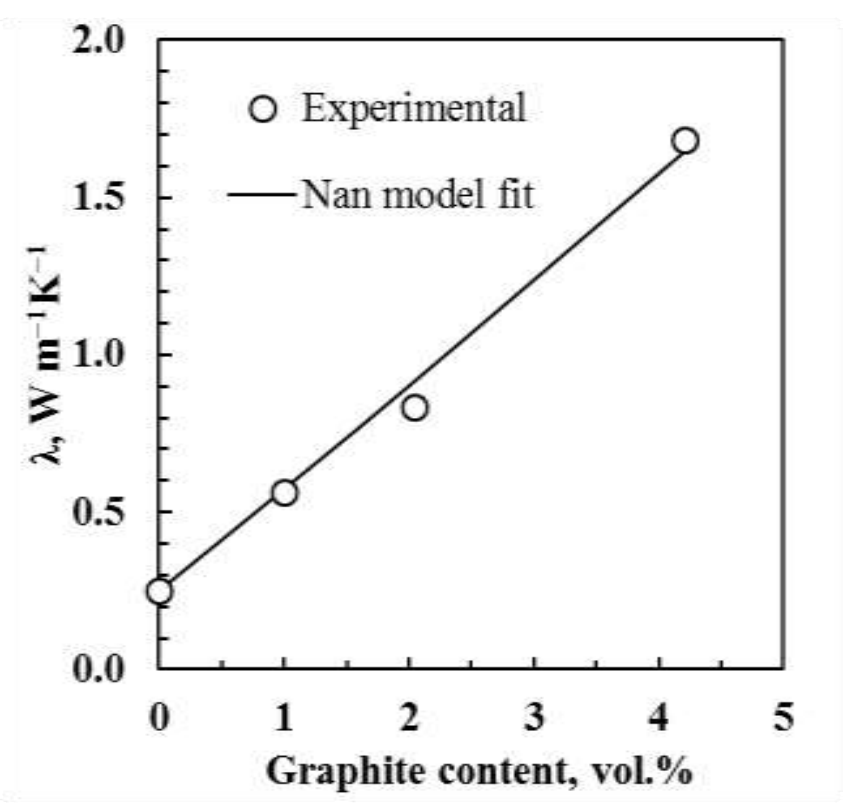

Figure 8. Fit of the Nan model [39] to the thermal conductivity $(\lambda)$ data of stearyl alcohol-palm triple pressed acid PCM-GNP nanocomposites in the solid state measured at $22^{\circ} \mathrm{C}$. The PCM phase contained 35 mol\% stearyl alcohol and the graphite loading was $10 \mathrm{wt} . \%$.

3.3.5. Thermal conductivity modelling. The thermal conductivity of PCMs containing dispersed conductive particles is influenced by the inherent conductivity of the two phases, the filler content, and the geometry, aspect ratio, and spatial orientation of the dispersed particles together with the nature of the interface between the PCM matrix and the particles [19]. Nan et al. [43] proposed a thermal conductivity model for particulate composites based on the Maxwell-Garnett-type effective medium approach. The Nan model, for isotropically oriented ellipsoidal particles, was applied to the present thermal conductivity data obtained for the PCM nanocomposites. The GNP particles were assigned a diameter equal to the $d_{50}$ value $(13 \mu \mathrm{m})$ and a thickness of $76 \mathrm{~nm}$. The graphite in-plane and through-plane conductivities were taken as $3000 \mathrm{~W} \mathrm{~m}^{-1} \mathrm{~K}^{-1}$ and $6 \mathrm{~W} \mathrm{~m}^{-1} \mathrm{~K}^{-1}$ respectively. Figure 8 shows 
the room temperature experimental data for the solid state together with a fit of the Nan model assigning an interfacial thermal resistance of $4.03 \times 10^{-8} \mathrm{~W}^{-1} \mathrm{~m}^{2} \mathrm{~K}$. This value for the interfacial thermal resistance is less than half the value previously reported for paraffin-based PCM-GNPs nanocomposites [42]. The improvement, i.e. the decrease in the interfacial thermal resistance, on replacing the entirely aliphatic paraffin compound with molecules capable of hydrogen bonding, supports the notion that stronger matrix-filler interactions may have enhanced the thermal conductivity.

3.3.6. Thermal stability. The thermal stability of the PCM-GNP nanocomposites was evaluated through accelerated thermal cycling tests and settling tests of the PCM-GNPs nanocomposite in the molten state. The accelerated cycling test is widely used to evaluate whether the PCM will undergo property deterioration [5, 13]. The PCM-GNPs nanocomposite of this study was subjected to 100 melt/freeze cycles in the DSC at a heating rate of $10^{\circ} \mathrm{C} \mathrm{min}^{-1}$. The advantage of using the DSC is that it provides immediate and direct indication of changes in the melting and crystallization behaviour with cycling. Figure 9 shows that there was, for all practical purposes, no such change over one hundred cycles for the PCM/GNP nanocomposite with 10 wt.\% GNPs. Previous studies showed high thermal stability for eutectic mixtures of a straight chain fatty acid and an $n$-alkanol [13]. The present study extended this to PCMs that include GNPs as filler.

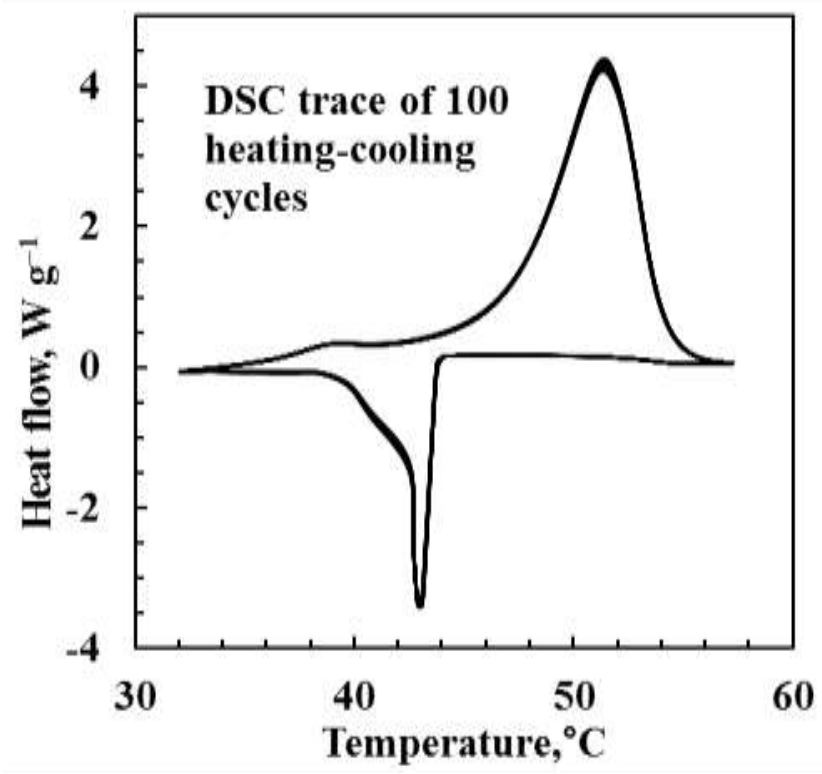

Figure 9. DSC thermal cycling stability testing via 100 melt/freeze cycles in the at a scan rate of $10^{\circ} \mathrm{C} \mathrm{min}^{-1}$. The PCM phase contained $35 \mathrm{~mol} \%$ stearyl alcohol and the graphite loading was $10 \mathrm{wt} . \%$. 
The settling tests (Figure S4 supplementary information) also showed that no settling of graphite particles occurred for the PCM-GNP nanocomposite with $10 \mathrm{wt} \%$ GNPs even after 60 days (1440 h). The GNPs remained well dispersed within the PCM matrices. In contrast, the nanocomposites containing $5 \mathrm{wt}$ \% or less GNPs were unstable over this time period. The conductive filler separated out and accumulated at the bottom of the vial. Such sedimentation is undesirable as the thermal conductivity enhancement will be compromised.

\section{Conclusions}

A mixture of stearyl alcohol (35 mol\%) with palm triple pressed acid (65 wt.\%) shows a single DSC endotherm peak and a single DSC exotherm peak at the melting and crystallization transitions respectively. The enthalpy change associated with these phase transformations is comparable to that of the palm triple pressed acid as it exhibits virtually no super cooling. This makes it a candidate phase change material for energy storage at low temperatures. The thermal conductivity of this phase change materials was improved several fold by adding graphite nanoplatelets at a loading of $10 \mathrm{wt} . \%$. This reduced the overall phase change enthalpy by about $16 \%$. However, no deterioration in thermal properties was observed after one hundred heating-melting and cooling-crystallization cycles. This high graphite loading also prevented particles from settling out of the liquid phase.

The effect of graphite loading on the thermal conductivity improvement was analysed with the Nan model. A good fit to the data was found for a value of the interfacial thermal resistance that is about half that previously found for a paraffin-based graphite nanocomposite heat storage material. This suggests that the observed thermal conductivity improvement might be due to the stronger hydrogen bonding interactions between matrix molecules and the conductive filler.

\section{Acknowledgements}

This work is based on the research supported by the South African Research Chairs Initiative of the Department of Science and Technology and National Research Foundation (NRF) of South Africa (Grant No. 97994), the African Laser Centre (ALC) and the Energy Institutional Research Theme of the University of Pretoria. Any opinion, finding and conclusion or recommendation expressed in this material is that of the authors and the NRF does not accept any liability in this regard. 


\section{References}

[1] B. Zalba, J.M. Marín, L.F. Cabeza, H. Mehling, Review on thermal energy storage with phase change: materials, heat transfer analysis and applications, Applied thermal engineering, 23 (2003) 251-283.

[2] A. Sharma, V. Tyagi, C. Chen, D. Buddhi, Review on thermal energy storage with phase change materials and applications, Renewable and Sustainable energy reviews, 13 (2009) 318-345.

[3] M.M. Farid, A.M. Khudhair, S.A.K. Razack, S. Al-Hallaj, A review on phase change energy storage: materials and applications, Energy conversion and management, 45 (2004) 1597-1615.

[4] Y. Cui, C. Liu, S. Hu, X. Yu, The experimental exploration of carbon nanofiber and carbon nanotube additives on thermal behavior of phase change materials, Solar Energy Materials and Solar Cells, 95 (2011) 1208-1212.

[5] Y. Yuan, N. Zhang, W. Tao, X. Cao, Y. He, Fatty acids as phase change materials: a review, Renewable and Sustainable Energy Reviews, 29 (2014) 482-498.

[6] J. Huang, S. Lu, X. Kong, S. Liu, Form-stable phase change materials based on eutectic mixture of tetradecanol and fatty acids for building energy storage: preparation and performance analysis, Materials, 6 (2013) 4758-4775.

[7] J. Zeng, Y. Liu, Z. Cao, J. Zhang, Z. Zhang, L. Sun, F. Xu, Thermal conductivity enhancement of MWNTs on the PANI/tetradecanol form-stable PCM, Journal of Thermal Analysis and Calorimetry, 91 (2008) 443-446.

[8] F. Yavari, H.R. Fard, K. Pashayi, M.A. Rafiee, A. Zamiri, Z. Yu, R. Ozisik, T. BorcaTasciuc, N. Koratkar, Enhanced thermal conductivity in a nanostructured phase change composite due to low concentration graphene additives, The Journal of Physical Chemistry C, 115 (2011) 8753-8758.

[9] J.C. van Miltenburg, H.A. Oonk, L. Ventola, Heat capacities and derived thermodynamic functions of 1-octadecanol, 1-nonadecanol, 1-eicosanol, and 1-docosanol between $10 \mathrm{~K}$ and 370 K, Journal of Chemical \& Engineering Data, 46 (2001) 90-97.

[10] L. Ventola, M. Ramirez, T. Calvet, X. Solans, M. Cuevas-Diarte, P. Negrier, D. Mondieig, J. Van Miltenburg, H. Oonk, Polymorphism of n-alkanols: 1-Heptadecanol, 1octadecanol, 1-nonadecanol, and 1-eicosanol, Chemistry of materials, 14 (2002) 508-517. [11] F.G. Gandolfo, A. Bot, E. Flöter, Phase diagram of mixtures of stearic acid and stearyl alcohol, Thermochimica acta, 404 (2003) 9-17. 
[12] J. Zeng, Z. Cao, D. Yang, F. Xu, L. Sun, L. Zhang, X. Zhang, Phase diagram of palmitic acid-tetradecanol mixtures obtained by DSC experiments, Journal of thermal analysis and calorimetry, 95 (2009) 501-505.

[13] J. Zuo, W. Li, L. Weng, Thermal performance of caprylic acid/1-dodecanol eutectic mixture as phase change material (PCM), Energy and Buildings, 43 (2011) 207-210.

[14] J. Zuo, W. Li, L. Weng, Thermal properties of lauric acid/1-tetradecanol binary system for energy storage, Applied Thermal Engineering, 31 (2011) 1352-1355.

[15] R. Velraj, R. Seeniraj, B. Hafner, C. Faber, K. Schwarzer, Heat transfer enhancement in a latent heat storage system, Solar energy, 65 (1999) 171-180.

[16] A. Sarı, A. Karaipekli, Thermal conductivity and latent heat thermal energy storage characteristics of paraffin/expanded graphite composite as phase change material, Applied Thermal Engineering, 27 (2007) 1271-1277.

[17] L. Fan, J. Khodadadi, Thermal conductivity enhancement of phase change materials for thermal energy storage: a review, Renewable and Sustainable Energy Reviews, 15 (2011) 2446.

[18] W. Mhike, W.W. Focke, J. Mofokeng, A.S. Luyt, Thermally conductive phase-change materials for energy storage based on low-density polyethylene, soft Fischer-Tropsch wax and graphite, Thermochimica Acta, 527 (2012) 75-82.

[19] J. Khodadadi, L. Fan, H. Babaei, Thermal conductivity enhancement of nanostructurebased colloidal suspensions utilized as phase change materials for thermal energy storage: a review, Renewable and Sustainable Energy Reviews, 24 (2013) 418-444.

[20] A. Elgafy, K. Lafdi, Effect of carbon nanofiber additives on thermal behavior of phase change materials, Carbon, 43 (2005) 3067-3074.

[21] J.-N. Shi, M.-D. Ger, Y.-M. Liu, Y.-C. Fan, N.-T. Wen, C.-K. Lin, N.-W. Pu, Improving the thermal conductivity and shape-stabilization of phase change materials using nanographite additives, Carbon, 51 (2013) 365-372.

[22] S. Shenogin, L. Xue, R. Ozisik, P. Keblinski, D.G. Cahill, Role of thermal boundary resistance on the heat flow in carbon-nanotube composites, Journal of Applied Physics, 95 (2004) 8136-8144.

[23] C.-W. Nan, G. Liu, Y. Lin, M. Li, Interface effect on thermal conductivity of carbon nanotube composites, Applied Physics Letters, 85 (2004) 3549-3551.

[24] G. Carotenuto, S. De Nicola, M. Palomba, D. Pullini, A. Horsewell, T.W. Hansen, L. Nicolais, Mechanical properties of low-density polyethylene filled by graphite nanoplatelets, Nanotechnology, 23 (2012) 485705. 
[25] D.D.L. Chung, Exfoliation of graphite, Journal of Materials Science, 22 (1987) 41904198.

[26] G. Chen, W. Weng, D. Wu, C. Wu, J. Lu, P. Wang, X. Chen, Preparation and characterization of graphite nanosheets from ultrasonic powdering technique, Carbon, 42 (2004) 753-759.

[27] B.Z. Jang, A. Zhamu, Processing of nanographene platelets (NGPs) and NGP nanocomposites: a review, Journal of Materials Science, 43 (2008) 5092-5101.

[28] M. Pimenta, G. Dresselhaus, M.S. Dresselhaus, L. Cancado, A. Jorio, R. Saito, Studying disorder in graphite-based systems by Raman spectroscopy, Physical chemistry chemical physics, 9 (2007) 1276-1290.

[29] A. Ksiazczak, B. Parczewska, Vapour pressures of binary three-phase (solid + liquid + vapour) mixtures I. Melting temperatures of polymorphic phases, The Journal of Chemical Thermodynamics, 20 (1988) 785-790.

[30] G.J. Maximo, N.D.D. Carareto, M.C. Costa, A.O. dos Santos, L.P. Cardoso, M.A. Krähenbühl, A.J.A. Meirelles, On the solid-liquid equilibrium of binary mixtures of fatty alcohols and fatty acids, Fluid Phase Equilibria, 366 (2014) 88-98.

[31] C. Tillotson, Some physical chemical properties of stearic acid, Journal of the society of cosmetic chemists, 6 (1955) 9.

[32] P. Zhao, Q. Yue, H. He, B. Gao, Y. Wang, Q. Li, Study on phase diagram of fatty acids mixtures to determine eutectic temperatures and the corresponding mixing proportions, Applied Energy, 115 (2014) 483-490.

[33] J.-L. Zeng, Y.-H. Chen, L. Shu, L.-P. Yu, L. Zhu, L.-B. Song, Z. Cao, L.-X. Sun, Preparation and thermal properties of exfoliated graphite/erythritol/mannitol eutectic composite as form-stable phase change material for thermal energy storage, Solar Energy Materials and Solar Cells, 178 (2018) 84-90.

[34] G.P. Stahly, A survey of cocrystals reported prior to 2000, Crystal Growth \& Design, 9 (2009) 4212-4229.

[35] M.C. Costa, M.P. Rolemberg, A.J. Meirelles, J.A. Coutinho, M. Krähenbühl, The solidliquid phase diagrams of binary mixtures of even saturated fatty acids differing by six carbon atoms, Thermochimica Acta, 496 (2009) 30-37.

[36] L. Rycerz, Practical remarks concerning phase diagrams determination on the basis of differential scanning calorimetry measurements, J Therm Anal Calorim, 113 (2013) 231-238. [37] G. Nichols, S. Kweskin, M. Frericks, S. Reiter, G. Wang, J. Orf, B. Carvallo, D. Hillesheim, J. Chickos, Evaluation of the vaporization, fusion, and sublimation enthalpies of 
the 1-alkanols: The vaporization enthalpy of 1-, 6-, 7-, and 9-heptadecanol, 1-octadecanol, 1eicosanol, 1-docosanol, 1-hexacosanol, and cholesterol at $\mathrm{T}=298.15 \mathrm{~K}$ by correlation gas chromatography, Journal of Chemical and Engineering Data, 51 (2006) 475-482.

[38] F.G. Gandolfo, A. Bot, E. Flöter, Structuring of edible oils by long-chain FA, fatty alcohols, and their mixtures, Journal of the American Oil Chemists' Society, 81 (2004) 1-6. [39] H. Schaink, K. Van Malssen, S. Morgado-Alves, D. Kalnin, E. Van der Linden, Crystal network for edible oil organogels: possibilities and limitations of the fatty acid and fatty alcohol systems, Food Research International, 40 (2007) 1185-1193.

[40] A.A. Aydın, Fatty acid ester-based commercial products as potential new phase change materials (PCMs) for thermal energy storage, Solar Energy Materials and Solar Cells, 108 (2013) 98-104.

[41] J. Wang, H. Xie, Z. Xin, Thermal properties of heat storage composites containing multiwalled carbon nanotubes, Journal of applied physics, 104 (2008) 113537.

[42] J. Xiang, L.T. Drzal, Investigation of exfoliated graphite nanoplatelets (xGnP) in improving thermal conductivity of paraffin wax-based phase change material, Solar Energy Materials and Solar Cells, 95 (2011) 1811-1818.

[43] C.-W. Nan, R. Birringer, D.R. Clarke, H. Gleiter, Effective thermal conductivity of particulate composites with interfacial thermal resistance, Journal of Applied Physics, 81 (1997) 6692-6699. 


\section{Supporting Information}

Table S1. Thermal decomposition data of polyaminofullerene nitrate.

\begin{tabular}{ccccc}
\hline$\beta\left(\mathrm{K} \cdot \mathrm{min}^{-1}\right)$ & $\mathrm{T}_{\mathrm{m}}(\mathrm{K})$ & $1 / \mathrm{T}_{\mathrm{m}} \times 10^{3}$ & $\ln \left(\beta \cdot \mathrm{T}_{\mathrm{m}}^{-2}\right)$ & $\log \beta$ \\
\hline 20 & $431.7(1)$ & $2.316(1)$ & $-9.140(1)$ & 1.301 \\
15 & $429.2(1)$ & $2.330(1)$ & $-9.416(1)$ & 1.176 \\
10 & $424.7(5)$ & $2.353(3)$ & $-9.802(4)$ & 1.000 \\
5 & $421.2(2)$ & $2.374(2)$ & $-10.477(1)$ & 0.699 \\
2.5 & $415.2(7)$ & $2.406(4)$ & $-11.144(3)$ & 0.398 \\
\hline
\end{tabular}

Table S2. Kinetic parameters of polyaminofullerene nitrate by means of model-free method.

\begin{tabular}{cccccc}
\hline \multirow{2}{*}{ Method } & \multicolumn{2}{c}{$\mathrm{E}_{\mathrm{a}} / \mathrm{kJ} \cdot \mathrm{mol}^{-1}$} & \multicolumn{2}{c}{$\ln \left(A / \mathrm{s}^{-1}\right)$} & \multirow{2}{*}{$\mathrm{R}^{2}$} \\
\cline { 2 - 5 } & Value & $\sigma$ & Value & $\sigma$ & \\
\hline Kissinger's method & 181.41 & 0.14 & 44.49 & 2.64 & 0.9893 \\
Ozawa's method & 187.05 & 0.06 & - & - & 0.9900 \\
\hline
\end{tabular}

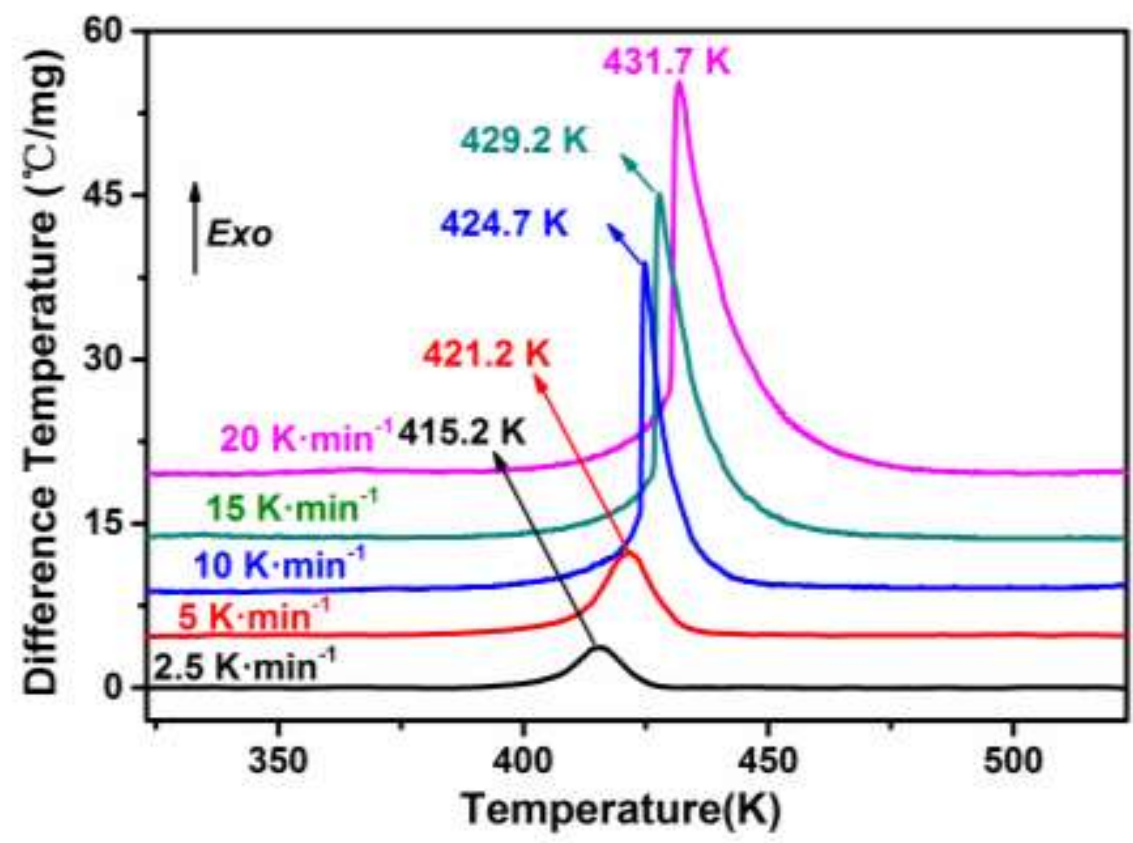

Figure S1. The DTA curves of polyaminofullerene nitrate at different temperature scan rates. 

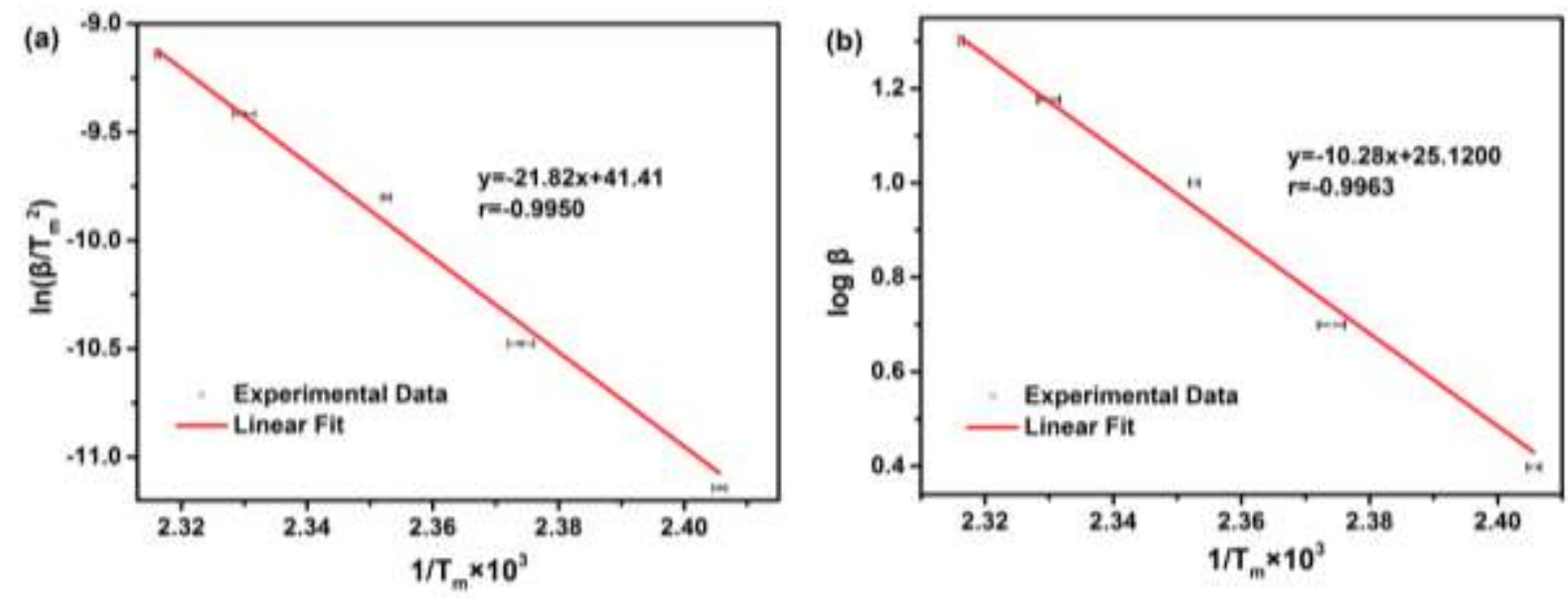

Figure S2. Plot of (a) $\ln \left(\beta \cdot T_{\mathrm{m}}{ }^{-2}\right)$ versus $T_{\mathrm{m}}{ }^{-1} \times 10^{3}$ and (b) $\log \beta$.

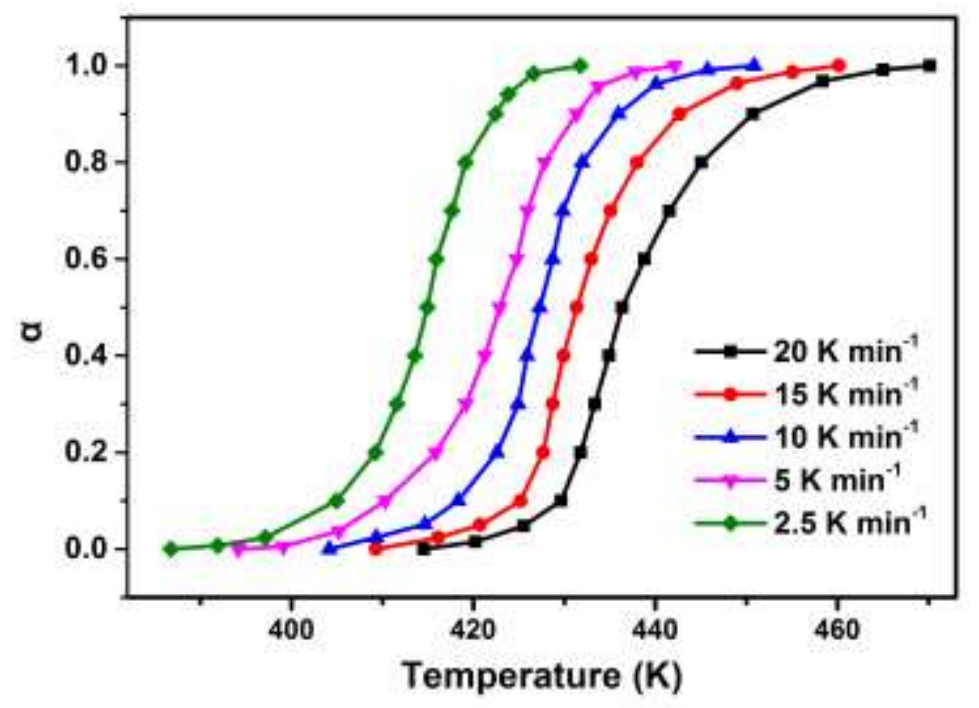

Figure S3. Conversion temperature curves $(\alpha-T)$ of polyaminofullerene nitrate at different temperature scan rates. 


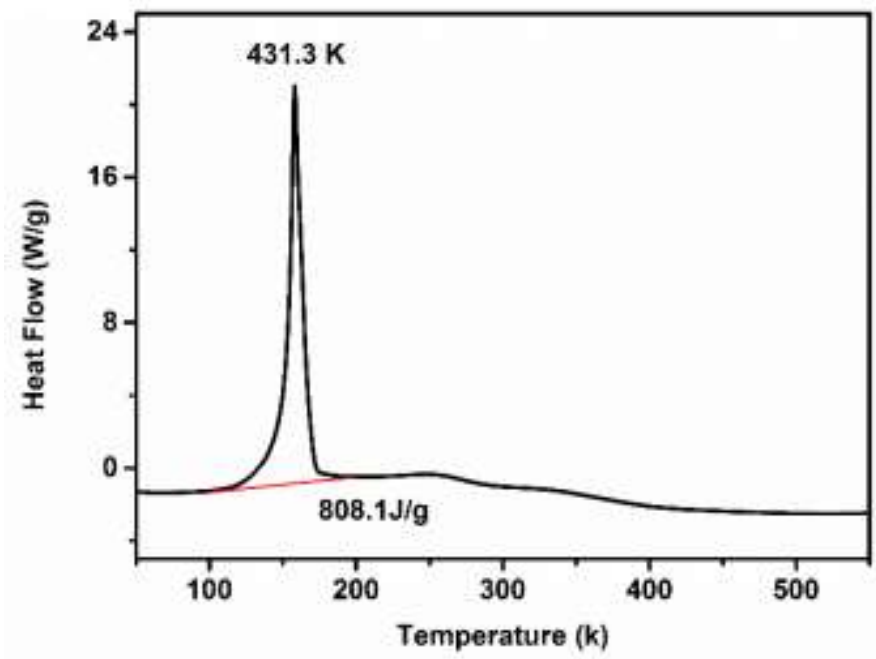

Figure S4. DSC curve of polyaminofullerene nitrate at a heating rate of $10 \mathrm{~K} \cdot \mathrm{min}^{-1}$. 